Goalwin, A., and Pomerannge, J. (1962). Archives of Pediatrics, 79, 58. Hansen, A. B., Wiese, H. F., and Adam, D. J. D. (1964). American fournal of Clinical Nutrition, 15, 11 .

Kwiterovitch, P. O., Levy, R. I., and Fredrickson, D. S. (1970). Circulation, 41-42, Suppl. No. III, p. il.

Lee, V. A. (1967). American fournal of Clinical Nutrition, 20, 5

Lees, G. B., Culley, G. A., Lawson, M. J., Adcock, L. L., and Krivit, W. (1969). Circulation, 39, 183.
Lewis, L. A., Brown, H. B., and Green, J. G. (1967). Circulation, 35-36, Suppl. No. II, p. 24

Mulligan, J. E., Roach, M. R., and Talner, W. S. (1969). Journal of the American Dietetic Association, 49, 309.

Oliver, M. F., and Boyd, G. S. (1955). Clinical Science, 14, 15

Salt, H. B., and Wolff, O. H. (1957). Archives of Disease in Childhood, 32, 404.

Slack, J. (1969). Lancet, 2, 1380.

Wolf, O. H. (1967). Proceedings of the Royal Society of Medicine, 20, 1147.

\title{
Effect of Nitrazepam in Chronic Obstructive Bronchitis
}

\author{
J. GADDIE, J. S. LEGGE, K. N. V. PALMER, J. C. PETRIE, R. A. WOOD
}

British Medical fournal, 1972, 2, 688-689

\section{Summary}

The effect of nitrazepam on ventilatory capacity and arterial blood gas tensions was studied in a double-blind controlled crossover trial in six patients with chronic obstructive bronchitis in ventilatory failure (raised $\mathbf{P a C O}_{2}$ ). Nitrazepam produced a fall in ventilatory capacity and worsening of the ventilatory failure. In the sixth patient, while on the active drug, the $\mathrm{PaO}_{2}$ fell from 48 to $35 \mathrm{~mm} \mathrm{Hg}$ while the $\mathrm{Paco}_{2}$ tension rose from 59.5 to $68 \mathrm{~mm} \mathrm{Hg}$. It is suggested that nitrazepam is contraindicated in patients with severe chronic obstructive bronchitis.

\section{Introduction}

Nitrazepam is a hypnotic drug which is finding increased clinical usage because of its efficacy and safety. Sleep is induced by depressing the activity of the amygdala and hippocampus (Schallek et al., 1965). Nitrazepam, like diazepam, another benzodiazepine derivative, also has central muscle relaxant properties (Svenson and Gordon, 1965).

In patients with normal lung function nitrazepam does not cause respiratory depression even when the normal therapeutic dosage is exceeded (Matthew et al., 1969). However, three patients with respiratory failure were noted to develop carbon dioxide narcosis after taking nitrazepam as night sedation (Clark et al., 1971). We have studied the effect of a therapeutic dose of nitrazepam $(10 \mathrm{mg})$ in patients with chronic obstructive bronchitis and hypercapnia in a double-blind controlled crossover trial.

\section{Patients and Methods}

Six men were investigated. Their mean age was 65 years (range 50-75), height 1.67 metres (range 1.53-1.78), and weight $58.3 \mathrm{~kg}$ (range 51-73). The nature of the trial was explained and they all gave their consent. All had smoked at least 10 cigarettes daily for a minimum of 20 years. They had been admitted to hospital because of an acute exacerbation of chronic obstructive bronchitis and were assessed for admission to the trial when they had recovered from the acute episode and were convalescent. The

Department of Medicine, University of Aberdeen

J. GADDIE, M.B., CH.B., Research Fellow

J. S. LEGGE, M.D., Research Fellow

K. N. V. PALMER, M.D., F.R.C.P., Reader

Department of Therapeutics and Clinical Pharmacology, University of Aberdeen

J. C. PETRIE, M.B., CH.B., M.R.C.P., Senior Lecturer

R. A. WOOD, B.SC., M.R.C.P.ED. Lecturer

diagnosis at this time was chronic obstructive bronchitis and ventilatory failure (Campbell, 1965; Palmer and Diament, 1970).

During the trial no change was made in concurrent drug therapy. Each patient was studied at the same time on two separate days, at least $\mathbf{4 8}$ hours apart. Arterial blood gas tensions and dynamic lung volumes were measured before and at 30minute intervals up to 120 minutes after either $10 \mathrm{mg}$ of nitrazepam or placebo by mouth, the order of giving the drugs being randomized. On each day, before beginning the study, arterial cannulation of the brachial artery was performed. Blood samples were obtained with a heparinlubricated syringe when the patients were breathing air, and the arterial oxygen tension $\left(\mathrm{PaO}_{2}\right)$, arterial carbon dioxide tension $\left(\mathrm{PaCO}_{2}\right)$, and $\mathrm{pH}$ were measured in duplicate with electrodes manufactured by Radiometer (Copenhagen). The standard deviation for a single measurement in our hands was $1.14 \mathrm{~mm} \mathrm{Hg}$ for the oxygen electrode and 1.02 $\mathrm{mm} \mathrm{Hg}$ for the carbon dioxide electrode. Forced expiratory spirograms were obtained and from the best of three attempts the forced vital capacity (FVC), forced expiratory volume in 1 second $\left(F E V_{1}\right)$, and the $F E V_{1}$ as a percentage of $F V C\left(F E V_{1} \%\right)$ were measured. Volumes were recorded in litres A.T.P.S. (ambient temperature and pressure saturated with water vapour). Normal values for spirometric measurements were derived by using the data of the Committee on Rating of Mental and Physical Impairment (1965), allowing for differences in age, sex, and height.

\section{Results}

The mean results of spirometry and arterial blood gas tensions in the six patients before admission to the trial are shown in Table I. Severe airways obstruction and a restrictive ventilatory defect were present. Hypoxaemia and hypercapnia were severe and the mean $\mathrm{pH}$ was within the normal range so that these patients had ventilatory failure with a compensated respiratory acidosis.

The mean falls in the dynamic lung volumes and blood gas tensions at intervals of 30 minutes for up to two hours after the drug compared with placebo are shown in Table II. The $F_{1}$ and FVC fell significantly $(P<0.01)$ compared with placebo and there was a fall in $\mathrm{PaO}_{2}$ and a tendency for the $\mathrm{PaCO}_{2}$ to rise compared with placebo.

TABLE I-Spirometry and Arterial Blood Gas Tensions in Six Patients with Chronic Obstructive Bronchitis

\begin{tabular}{|c|c|c|c|c|}
\hline \multicolumn{3}{|c|}{ Measurement } & \multirow{2}{*}{$\begin{array}{l}\text { Mean (Range) } \\
0 \cdot 62(0 \cdot 31-0.91) \\
1 \cdot 71(1 \cdot 01-2 \cdot 25) \\
36.4(29 \cdot 0-51 \cdot 5) \\
48.5(32 \cdot 0-55.0) \\
58.4(53 \cdot 0-69 \cdot 0) \\
7.42(7 \cdot 37-7 \cdot 48)\end{array}$} & \multirow{2}{*}{$\begin{array}{c}\begin{array}{c}\text { Mean } \\
\text { Predicted } \\
\text { Normal Values }\end{array} \\
2 \cdot 6 \\
3 \cdot 4 \\
76.5\end{array}$} \\
\hline 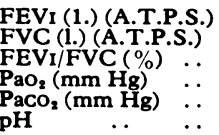 & $\begin{array}{l}\ldots \\
\because \\
\cdots \\
\cdots\end{array}$ & $\begin{array}{l}\because \\
\because \\
\because \\
\because\end{array}$ & & \\
\hline
\end{tabular}


TABLE II-Mean Changes in Dynamic Lung Volumes and Arterial Blood Gas Tensions in Six Patients with Chronic Obstructive Bronchitis

\begin{tabular}{|c|c|c|c|c|c|c|c|c|c|c|}
\hline & \multicolumn{10}{|c|}{ Time in Minutes } \\
\hline & \multicolumn{2}{|c|}{ Basal } & \multicolumn{2}{|c|}{30} & \multicolumn{2}{|c|}{60} & \multicolumn{2}{|c|}{90} & \multicolumn{2}{|c|}{120} \\
\hline & A & $\mathbf{P}$ & $\mathbf{A}$ & $\mathbf{P}$ & $\mathbf{A}$ & $\mathbf{P}$ & $\mathbf{A}$ & $\mathbf{P}$ & $\mathbf{A}$ & $\mathbf{P}$ \\
\hline $\begin{array}{l}\text { FEVI } \\
\text { FVC } \\
\mathrm{FEVI}_{1} \% \\
\mathrm{PaO}_{2} \\
\mathrm{PaCO}_{2} \\
\mathrm{pH}\end{array}$ & $\begin{array}{l}0.63 \\
1.78 \\
35 \cdot 4 \\
49 \cdot 3 \\
60.5 \\
7 \cdot 41\end{array}$ & $\begin{array}{c}0.60 \\
1.83 \\
32.9 \\
47.7 \\
59.7 \\
7.39\end{array}$ & \begin{tabular}{|c|}
0.60 \\
1.79 \\
33.5 \\
48.9 \\
60.0 \\
7.41
\end{tabular} & \begin{tabular}{|c|}
0.59 \\
1.76 \\
33.5 \\
46.4 \\
59.8 \\
7.40
\end{tabular} & $\begin{array}{c}0.57 \\
1.66 \\
34.3 \\
47 \cdot 3 \\
60.9 \\
7.41\end{array}$ & $\begin{array}{c}0.60 \\
1.85 \\
32.4 \\
45.7 \\
59 \cdot 3 \\
7.40\end{array}$ & $\begin{array}{c}0.57 \\
1.62 \\
35.2 \\
47.1 \\
61.8 \\
7.41\end{array}$ & $\begin{array}{c}0.61 \\
1.82 \\
33.6 \\
46.8 \\
59.8 \\
7.40\end{array}$ & \begin{tabular}{|c|}
$0.51 *$ \\
$1.36^{*}$ \\
37.5 \\
46.8 \\
62.9 \\
7.40
\end{tabular} & $\begin{array}{c}0.61 \\
1.84 \\
33.2 \\
47 \cdot 3 \\
60.0 \\
7.40\end{array}$ \\
\hline
\end{tabular}

$\mathrm{A}=$ Nitrazepam $10 \mathrm{mg} . \mathrm{P}$
${ }^{\mathrm{D}}$ Difference between $\mathrm{A}$ and $\mathrm{P}$ significant at $1 \%$ level.

The sixth patient was studied for four hours because it was noted that the fifth patient appeared to become increasingly confused between two and four hours on the active drug. In the sixth patient, while on the active drug, the $\mathrm{PaO}_{2}$ fell by 13.0 $\mathrm{mm} \mathrm{Hg}$ from 48 to $35 \mathrm{~mm} \mathrm{Hg}$ while the $\mathrm{PaCO}_{2}$ tension rose by $8.5 \mathrm{~mm} \mathrm{Hg}$ from 59.5 to $68.0 \mathrm{~mm} \mathrm{Hg}$. It was thought unethical to continue the trial.

\section{Discussion}

Ventilatory capacity fell quite appreciably at 120 minutes after the ingestion of $10 \mathrm{mg}$ of nitrazepam in these patients with severe chronic obstructive bronchitis and hypercapnia. There was a tendency for the arterial oxygen tension to fall and the hypercapnia to increase. These changes in blood gas tensions seemed to develop later than the changes in the spirometric measurements.

Intravenous diazepam has been shown to reduce the ventilatory capacity in an uncontrolled study of patients with obstructive lung disease, leading to a mean increase in arterial carbon dioxide tension of $3.5 \mathrm{~mm} \mathrm{Hg}$ (Catchlove and Kafer, 1971). Although it is impossible in the present study to separate the sedative and muscle relaxant properties of nitrazepam, the fall in ventilatory capacity is pronounced. In our sixth patient, who was studied for four hours, there were major changes in blood gas analysis. The other five patients were studied for only two hours because nitrazepam is expected to induce sleep within 45 minutes (Rutishauser, 1965).

It is well known that sedatives such as barbiturates are contraindicated in patients with ventilatory failure. There is a tendency to regard nitrazepam as a "safe hypnotic" (Matthew et al., 1969). Nitrazepam is prescribed in clinical practice for patients with severe respiratory disease, and indeed three of our patients had received it before admission, though an association with a deterioration in respiratory function has been suggested (Clark et al., 1971). The present study indicates that nitrazepam is contraindicated in patients with severe chronic obstructive bronchitis. Probably no sedative or tranquillizing drug is completely safe in these patients.

Our thanks are due to Dr. A. F. MacDonald for performing the arterial cannulations, to Dr. Gordon Hems for statistical advice, and to Mr. Keith Minty for technical assistance.

Requests for reprints should be addressed to Dr. K. N. V. Palmer, University Department of Medicine, Foresterhill, Aberdeen AB9 2ZD.

\section{References}

Campbell, E. J. M. (1965). British Medical fournal, 1, 1451.

Catchlove, R. F. H., and Kafer, E. R. (1971). Anesthesiology, 34, 13

Clark, T. J. H., Collins, J. V., and Tong, D. (1971) Lancet, 737.

Committee on Rating of Mental and Physical Impairment (1965). Fournal

of the American Medical Association, 194, 919. Wright, N. (1969). British Medical fournal, 3, 23.

Palmer, K. N. V., and Diament, M. L. (1970). Thorax, 25, 101.

Palmer, K. N. V., and Diament, M. L. (1970). Thorax, 25, 101.

Schallek, W., Thomas, J., Kuehn, A., and Zabransky, F. (1965). International fournal of Neuropharmacology, 4, 317.

Svenson, S. E., and Gordon, L. E. (1965). Current Therapeutic Research, Clinical and Experimental, 7, 367.

\section{PRELIMINARY COMMUNICATIONS}

\section{Nephrosonography in Infants and Children: A New Technique}

\author{
E. A. LYONS, J. E. E. FLEMING, G. C. ARNEIL, \\ A. V. MURPHY, E. M. SWEET, IAN DONALD
}

British Medical Fournal, 1972, 2, 689-691

\section{Summary}

A technique has been developed for the ultrasonic investigation of renal disease in infants using a specially designed water-bath with a conventional ultrasonic scanner. This permits ultrasonic studies of the renal tract from the neonatal period onwards; the procedure does not distress the child and the water acts as an excellent coupling medium.

Department of Ultrasonics, Queen Mother's Hospital, Glasgow C.3 E. A. LYONS, M.D., Seconded from Winnipeg General Hospital, Manitoba, Canada

IAN DONALD, M.D., F.R.c.s., Regius Professor, Midwifery

J. E. E. FLEMING, Research Technician

Royal Hospital for Sick Children, Glasgow C.3

A. V. MURPHY, M.B., M.R.C.P., Lecturer, Department of Child Health G. C. ARNEIL, M.D., F.R.C.P., Professor, Department of Child Health E. M. SWEET, M.B., F.R.C.P., Consultant Radiologist

\section{Introduction}

Investigation of the urinary tract of the young child is generally confined to procedures which depend on the presence of some degree of renal function. In a number of conditions such as hydronephrosis and cystic disease little or no function may be present in a kidney, and it may be difficult to assess the degree of dilatation and the extent of parenchymal damage by intravenous urography. Successful retrograde pyelography and nephrotomography may supply some additional information but are rarely used in the infant as the former is a difficult and hazardous operative procedure and the latter incurs a relatively large dose of radiation.

Holmes (1966) and Barnett and Morley (1971) showed ultrasound to be a safe, non-surgical technique in the investigation of the urinary tract in adults. They reported its usefulness in differentiating between renal cysts and tumours, in assessing hydronephrosis, and in visualizing bladder tumours. Hünig and Ameri (1970) illustrated some uses of ultrasound in children with contact B scanning. Although this is the most widely accepted method of obtaining information by ultrasound it was found by us to be unsuitable for examining most infants aged less than 2 years even when under sedation and asleep. However gently applied, the rocking motion of the transducer across the patient's back was irritating and caused the child to squirm. In order to overcome this difficulty a water-bath has been specifically designed for infants from birth onwards to provide the maximal exposure with a minimum of patient 